\title{
¿NOS SEGUIMOS GUIANDO POR LOS ESTEREOTIPOS CUANDO \\ HABLAMOS SOBRE EL ANDALUZ?
}

\author{
ROSA MARÍA TRUJILLO UNQUILES ${ }^{1}$ \\ INGRID GIL ${ }^{2}$
}

Fecha de recepción: junio de 2020

Fecha de aceptación y versión definitiva: mayo de 2021

\begin{abstract}
RESUMEN: Este estudio analiza la situación actual del andaluz en los medios de comunicación partiendo de la hipótesis de que el andaluz está desprestigiado y estereotipado. A lo largo de este trabajo, hemos observado que, en efecto, se trata a los andaluces de forma discriminatoria por su forma de hablar. Existen estereotipos con respecto a los andaluces y su manera de comunicarse, y los medios de comunicación difunden falsos tópicos sobre el andaluz, que afectan de manera negativa a la población andaluza.
\end{abstract}

PaLABRAS Clave: andaluz; inferioridad; medios de comunicación; estereotipo; hablismo.

\section{Are we still guided by stereotypes when we talk about the Andalusian dialect?}

ABSTRACT: This study analyses the current situation of Andalusians in mass media based on the hypothesis that Andalusians are discredited and stereotyped. Throughout this study, we have observed that Andalusians are treated in a discriminatory manner because of their way of speaking. There are stereotypes regarding Andalusians and their way of communicating, and mass media spread false stereotypes about Andalusians, which negatively affect the Andalusian population.

KEY WORDS: Andalusian; inferiority; mass media; stereotype; accentism.

1 Estudiante titulada del Doble Grado en Relaciones Internacionales y Traducción e Interpretación. Universidad Pontificia Comillas. Correo electrónico: rosamariatrujillounquiles@gmail.com.

2 Profesora del departamento de Traducción e Interpretación y Comunicación Multilingüe. Universidad Pontificia Comillas. Correo electrónico: ingrid.gil@comillas.edu. 


\section{INTRODUCCIÓN}

En un momento en el que el mundo está cada vez más globalizado, en el que se supone que hemos avanzado en cuestiones sociales más que nunca, en el que comprendemos la diversidad y abrazamos un mundo diverso en el que nos comunicamos digitalmente más allá de las fronteras de nuestros pueblos y ciudades, increíblemente, todavía existen tendencias que ridiculizan algunas variedades del español. El habla se ha convertido en un arma para desprestigiar y para burlarse de otros (Limón, 2017).

En este artículo, nos enfocaremos en el andaluz, una variante del español desprestigiada socialmente y asociada a estereotipos negativos. Los andaluces crecemos pensando que nuestra manera de comunicarnos es inferior a la del resto de españoles. Todo ello se debe a que, desde hace mucho tiempo, y con mucho tiempo nos referimos a siglos, el andaluz ha sido criticado y estereotipado en España. De manera injusta e injustificada, el andaluz se ha equiparado a inculto, analfabeto, gracioso, incomprensible, fiestero, pobre y vago. Se ha considerado un dialecto lingüísticamente incorrecto e inferior a otros dialectos por encontrarse muy alejado del supuesto dialecto superior: el español neutro (López González, 2018).

Desde pequeños, nos enseñan que debemos intentar comunicarnos con un habla superior: el «español estándar», basado en las características del habla del centro-norte del país. En este sentido, los medios de comunicación (televisión, radio, internet, libros y ambiente externo) han sido los grandes responsables de la divulgación de muchos de los estereotipos que en la actualidad existen sobre el andaluz. Todos estos estereotipos carecen de objetividad y fundamentos científicos y académicos (López González, 2018). Por ello, bajo la premisa de que el andaluz ha sido menospreciado a lo largo del tiempo y que los medios de comunicación han sido los principales causantes de ese desprestigio, el principal objetivo de este artículo será la defensa del andaluz y la diversidad lingüística desde una base científica y objetiva, no sujeta a los estereotipos.

\section{METODOLOGÍA}

Para el desarrollo de este trabajo, hemos utilizado diversos recursos. En primer lugar, destacamos tres libros que han sido esenciales: La dignidad del habla andaluza de María Nieves López González (2018); El idioma andaluz. ¿Es el andaluz un idioma? de Miguel Heredia Jiménez (2018); y Perspectivas 
sobre la identidad andaluza. Políticos, intelectuales y ciudadanía de Xavier Coller (2014).

En segundo lugar, hemos analizado diferentes noticias de revistas, periódicos en línea y otros recursos virtuales: Libertad Digital, El Confidencial, eldiario.es, El Economista, La Marea, Huffpost, La Vanguardia, Ideal, Revista de pensamiento andaluz, ABC Andalucía, Córdoba buenas noticias, Fundéu, Biblioteca Virtual Miguel de Cervantes, El Español, Real Academia Española, El Periódico y Facebook.

En tercer lugar, hemos examinado diversos informes y ensayos de autores como: Aintzane Belamendia Alegria, José Luis Carrascosa Pulido, Marta Léon-Castro Gómez (Universidad de Sevilla), Anne Cenname (Research Gate), José Jesús de Bustos Tovar, María del Rosario Llorente Pinto, Mendoza Abreu, Manuel Muñoz Navarrete, Hans-J. Niederehe, Clara Ramos López (Universidad Pompeu Fabra) y Leticia Ureña Rodríguez (Universidad de Málaga).

En cuarto lugar, hemos analizado diversas películas, series de televisión y emisoras de radio como: Canal Sur Radio y Televisión, Radio y Televisión Española, Netflix (Ocho apellidos vascos) y Canal Sur.

Por último, hemos realizado una encuesta a 219 personas para conocer su opinión personal sobre el dialecto andaluz. Las encuestas son un método muy efectivo para conseguir información por varios motivos: por el ahorro de tiempo (envío y recepción inmediatos), la comodidad de poder responder cuando uno quiera, el bajo coste de su elaboración, la rapidez para obtener resultados, la calidad de los resultados (transparencia del anonimato) y el gran alcance que tiene (Rocco y Oliari, 2007). De las 219 personas encuestadas, $38,8 \%$ han nacido en Andalucía y el $61,2 \%$ han nacido fuera de Andalucía.

En cuanto a la elaboración de la encuesta, hemos utilizado la herramienta en línea Google Forms porque se trata de una plataforma gratuita, fácil de utilizar, eficiente, rápida de analizar y sencilla de difundir. Asimismo, se puede personalizar y crear una gran variedad de preguntas con ella (Datascope, 2018). Con respecto a las preguntas, hemos desarrollado un total de 19: cuatro han sido preguntas abiertas (el encuestado responde con sus propias palabras); 11 preguntas cerradas de elección única dicotómicas (el encuestado elige una única opción de las dos que se le plantean, generalmente «si» o «no»); una pregunta cerrada de elección única politómica (el encuestado elige una única opción de las varias alternativas que se le plantean); una pregunta cerrada de elección múltiple (el encuestado puede elegir varias opciones de las alternativas que se le plantean); y dos preguntas mixtas (el encuestado puede elegir varias opciones de las alternativas que se le plantean y proponer otras posibilidades de forma abierta), (Jibaro X, 2019). 
Las preguntas de la encuesta se han dividido en cuatro secciones: una introducción para conocer al encuestado, una parte sobre los medios de comunicación y los estereotipos, otro apartado sobre las motivaciones de los estereotipos y, por último, una sección sobre el vocabulario andaluz y posibles recomendaciones. Las preguntas han sido las siguientes:

a. ¿Has nacido en Andalucía?

Sí

No

b. ¿Ha vivido en Andalucía durante más de 10 años?

Sí

No

c. ¿Se considera o se siente andaluz?

Sí

No

d. ¿Cree que los andaluces (en general) están orgullosos de su acento y de su tierra?

Sí, de ambos

Sí, pero solo de su tierra

Sí, pero solo de su acento

No, de ninguno

e. ¿Considera que el andaluz es un dialecto inferior al resto de dialectos de España?

Sí

No

f. ¿Cree que los medios de comunicación, como la televisión y la radio, promueven los falsos estereotipos del andaluz?

Sí

No

g. ¿Recuerda alguna serie de televisión, película, canal de radio, etc. que utilicen a un personaje andaluz de manera humorística?

Sí

No

h. Si la respuesta anterior es afirmativa, indíquenos algún ejemplo:

i. Señale, por favor, si alguna vez ha escuchado algún comentario parecido a los siguientes dirigido a una persona andaluza. Puede seleccionar más de uno:

- ¡Tu acento me hace mucha gracia!

- ¡No entiendo nada de lo que dices!

- ¡Qué gracioso/a eres!

- ¡Tu acento no es tan fuerte para ser andaluza!

- ¡Los andaluces son catetos!

- ¡Los andaluces son de pueblo! 
- ¡Los andaluces se comen las letras!

- ¡Los andaluces son vagos!

- ¡Los andaluces solo entienden de fiestas!

j. Si conoce algún estereotipo más y desea compartirlo con nosotros, agradeceríamos que lo indicase en el siguiente espacio:

k. Por favor, marque las opciones con las que usted esté de acuerdo.

- No creo que el andaluz se considere inferior al castellano neutro

- En Andalucía hay muchos analfabetos

- El andaluz es una malformación del castellano

- Andalucía es una región pobre

- Los andaluces son vagos

- Andalucía está menos desarrollada

- El problema es que en Andalucía casi siempre han gobernado los partidos de izquierda

- Los andaluces aportan menos dinero al país (al PIB de España)

- Los andaluces reciben demasiado dinero del Estado que no se merecen

- Andalucía es tierra de ganaderos y agricultores

- Los andaluces son incultos

- Los andaluces son de pueblo y, por tanto, hablan mal

- Existe un español neutro y no es el andaluz

- Las personas que consideran que el andaluz es inferior al resto de dialectos del castellano ignoran la historia lingüística de España

- Otra:

1. ¿Cree que los estereotipos tienen consecuencias negativas para los andaluces?

Sí

No

m. ¿Podría decirme alguna consecuencia negativa que estos estereotipos podrían causar en la vida de los andaluces?

- Los estereotipos no tienen ninguna consecuencia negativa para los andaluces

- Las políticas del gobierno de España no intentan favorecer a Andalucía

- El resto de los españoles no toman en serio a los andaluces

- Dificultad de acceso al trabajo

- Complejo de inferioridad

- Los andaluces aceptan que «hablan mal»

- Los andaluces creen que su nivel cultural es menor

- Los andaluces creen que su sistema educativo es más fácil y menos reconocido

- Sensación de desprecio por el resto de España 
- Vergüenza al hablar

- Intento de cambiar el acento andaluz cuando hablan con personas no andaluzas

- Los propios andaluces corrigen a otros andaluces para que hablen «más correcto» (el dialecto "castellano neutro» que, en realidad, nadie habla)

- Exageración del acento andaluz para «hacerse la/el graciosa/o» en ciertas ocasiones

- Otra:

$\bullet$

n. ¿Cree que el vocabulario andaluz se entiende en el resto de España?

Sí

No

o. ¿Cree que todo vocabulario de una zona de Andalucía se entiende en todo el conjunto andaluz?

Sí

No

p. ¿A excepción de los vulgarismos propios de cada lengua y dialecto, cree que los andalucismos (términos propios del andaluz) son vulgares en general?

Sí

No

q. ¿Cree que los andaluces deberían seguir utilizando las palabras características de su región o deberían adaptarse al vocabulario propio del «castellano neutro»?

- Los andaluces deberían seguir utilizando las palabras características de su tierra

- Los andaluces deberían adaptarse al vocabulario propio del «castellano neutro»

r. ¿Conoce alguna palabra andaluza que sepa que no se entiende en el exterior de Andalucía o incluso fuera de una localidad o región concreta? Si es así, indique esa palabra y el significado que usted interprete.

s. Por último, si tiene alguna sugerencia para mejorar la dignidad del dialecto andaluz o algún proyecto que quiera compartir con nosotros, agradeceríamos que la escribiese en el siguiente espacio.

En relación con la difusión de la encuesta, se ha distribuido a través de las redes sociales más conocidas, como WhatsApp, Facebook e Instagram. El objetivo era que lo respondiesen tanto personas andaluzas, como de fuera de Andalucía para conseguir opiniones variadas y objetivas. 


\section{MARCO TÉÓRICO}

\section{1. ¿QUÉ ES EL ANDALUZ?}

Antes de todo, nos gustaría explicar por qué hemos decidido referirnos al andaluz cómo dialecto y no como variedad lingüística, lengua o habla. El problema reside en que los propios lingüistas no se ponen de acuerdo a la hora de definir los términos «lengua», «idioma», «dialecto», «modalidad o variedad regional», "habla regional» y «habla local». En muchos escritos, nos encontramos el término "andaluz» referido a lengua, variedad, habla o dialecto. Por ello, hemos decidido diferenciarlos y jerarquizarlos para determinar qué es exactamente el andaluz (Alvar, 2006).

Hemos observado que una "lengua» debe tener tanto un lenguaje hablado, como escrito; debe contar con unas normas y una gramática consolidadas; debe estar lo suficientemente diferenciada de otras lenguas; y debe poseer dialectos y variedades lingüísticamente subordinadas (Alvar, 2007). En cuanto al término «dialecto», todas las lenguas son dialectos de aquellas lenguas de las que proceden (lengua mayor o histórica). El latín procede del indoeuropeo, el castellano del latín y así sucesivamente. Además, un dialecto tiene normalmente una concreta limitación geográfica y una cierta diferenciación, dado que, si tuviese una gran diferenciación, se convertiría en lengua (Alvar, 2006). La «variedad lingüística» se refiere a la gran cantidad de usos que tiene una lengua según el contexto histórico (variedad diacrónica), el nivel formal e informal de cada acto comunicativo (variedad diafásica), el nivel cultural de la persona (variedad diastrática) y el lugar en el que se encuentre un hablante (variedad diatópica) (Ramos López, 2017). Por lo que respecta a las «hablas regionales», hemos observado que se refieren a las características particulares de un territorio concreto, en disconformidad con el dialecto al que pertenece. Por último, dentro de las hablas regionales, encontramos dos subsistemas más: el «habla local» (matices representativos de pequeñas zonas geográficas dentro de un territorio concreto que también tiene su propia habla regional) y el «idiolecto» (conjunto de rasgos propios de la forma de expresarse de un individuo) (Alvar, 2007).

Una vez analizados los términos anteriores, hemos determinado que el andaluz es un dialecto por varias razones: no es una lengua porque no tiene ortografía, gramática y literatura propias y porque su diferenciación de la lengua castellana no es tan grande como para considerarse otra lengua; por el contrario, consideramos que se trata de un dialecto porque tiene una ligera diferenciación de la lengua común de la que procede (en sus estructuras fonético-fonemáticas y modo-sintácticas), existe una limitación geográfica 
en el área de Andalucía, y la lingüística es heterogénea en su territorio; es decir, dentro del dialecto andaluz encontramos muchas hablas regionales y locales diferentes, propio de los dialectos. A modo de ejemplo, el ceceo, seseo y la distinción de la s no tienen lugar en todo el territorio. Por ello, es fácil distinguir a un sevillano, de un malagueño o un almeriense, por ejemplo (Alvar, 2006).

\subsection{ORIGEN DEL ANDALUZ}

Como hemos mencionado anteriormente, desde la Edad Media, se ha desprestigiado al andaluz por el hecho de no tratarse de la lengua hablada en la Corte de Castilla. En efecto, el andaluz es diferente al castellano. No podemos negar esta realidad, muy clara en la fonética andaluza. Pero hemos observado que esta disimilitud procede de una diferente evolución lingüística del latín vulgar, del que también procede el castellano. El hecho de que el castellano se impusiese como lengua oficial del país se produjo por casualidades de la historia y reside únicamente en causas extralingüísticas (López González, 2018).

El andaluz es una lengua romance que procede del latín vulgar de los colonizadores romanos. Tras la fragmentación del Imperio Romano (de Occidente y Oriente), el latín dio lugar a numerosos dialectos que más tarde se convirtieron en lenguas. En ese momento, en España se hablaba una especie de latín clásico con influencias prerromanas. Justo después, distintas tribus invadieron España, pero no impusieron su lengua al territorio. Sin embargo, los árabes sí que impusieron su lengua en Al-Ándalus y la mezclaron con la anterior lengua romance, creando una lengua criolla: el mozárabe. Durante esta época, solo una pequeña franja en el norte no conquistado mantuvo su lengua romance (Manzano, 2017).

En el momento de la reconquista, la Corte reconquistadora procedente del norte hablaba castellano e intentaron imponer su dialecto al resto de regiones de la península para unificar el territorio. La reconquista suscitó que el castellano y andaluz se uniesen, de tal forma que una gran cantidad de palabras de origen árabe se incluyeron en el alfabeto castellano. Desde ese momento, el andaluz, lengua criolla procedente del latín vulgar, con diversas influencias (aljamiada, mozárabe, latina y castellana) comenzó a evolucionar hasta convertirse en lo que actualmente conocemos como andaluz (Manzano, 2017). 


\section{ANÁLISIS}

\subsection{ANÁLISIS DE MEDIOS}

A pesar de que el andaluz debería considerarse tan válido como el resto de dialectos, lenguas o hablas de España, a lo largo de los años, se ha desprestigiado en todos los medios de comunicación posibles. Algunos autores sostienen que la libertad lingüística está aumentando y que muchas personas están reivindicando su dialecto en público, como lo han hecho María Teresa Campos y Paz Padilla, ambas presentadoras de televisión. Sin embargo, no ha sido suficiente y todavía queda un largo camino por recorrer. Todavía nos seguimos sorprendiendo al escuchar presentadores o personajes que tienen rasgos marcados de algún dialecto español. De hecho, el 79,9\% de las personas encuestadas para este artículo afirman que los medios de comunicación promueven falsos estereotipos sobre el andaluz. Este hecho ha afectado de manera negativa a los andaluces en diferentes aspectos de su vida, que veremos más adelante. Antes de todo, mostraremos ejemplos de falsos tópicos sobre el andaluz que diferentes medios de comunicación han difundido a lo largo de los años (López González, 2018).

\subsubsection{Internet: noticias y foros}

En primer lugar, destacamos la siguiente noticia encontrada en internet: En 2015, se celebró una rueda de prensa tras la derrota de la Sociedad Deportiva Eibar contra el equipo del Almería. El entrenador del Eibar (Gaizka Garitano) respondió a las preguntas en euskera y los periodistas de Almería no pudieron entender nada de lo que respondió el entrenador. Más tarde, la presentadora del programa de televisión Cuatro (Samanta Villar) escribió en Twitter lo siguiente: «Hay que entender a esos pobres periodistas deportivos de Almería. A duras penas entienden el castellano» (Ramos López, 2017, pp. 49). Todos los andaluces lo interpretaron como un insulto y criticaron esta publicación de Samanta Villar. Esta periodista había ofendido a los almerienses. Al día siguiente, Samanta Villar tuvo que disculparse (Ramos López, 2017). Este caso es un claro ejemplo del mito de que los andaluces no saben hablar, ni entender el castellano. Además, con las palabras «a duras penas entiende el castellano» interpretamos que quiere decir que los andaluces hablan otro idioma, lo que tampoco es cierto porque el andaluz es un dialecto, no un idioma.

Asimismo, también destacamos la gran polémica que tuvo la serie La Peste, estrenada en 2018. Esta serie recibió numerosas críticas por el hecho 
de que los personajes hablasen en andaluz. La historia estaba basada en la ciudad de Sevilla del siglo XVI, por ello, los personajes debían utilizar la variedad lingüística sevillana. Sin embargo, el dialecto andaluz no agradó a muchos de sus espectadores. Algunos de los comentarios que pusieron en Twitter fueron: "[...] Voy a ver si la encuentro doblada al inglés porque en castellano no se les entiende [...]», «Me cuesta entender nítidamente lo que dicen algunos actores ya que, consecuentemente, hablan con acento andaluz $[\ldots] »$ o «[...] La serie es buenísima pero tiene el problema de siempre: que no se entiende la mitad de las frases que dicen» (Cantó, 2018). En estos comentarios observamos un prejuicio muy importante: el mito de la ininteligibilidad andaluza. En otras palabras, la creencia de que el andaluz no se entiende fuera de las fronteras de Andalucía (Cantó, 2018).

También nos gustaría mostrar uno de los tantos comentarios que hemos encontrado en los foros de internet, en concreto, en el conocido foro de ForoCoches. En 2012, un tal Jomoru publicó lo siguiente: «Yo a los únicos que entiendo son a los sevillanos, a los demás me cuesta entenderlos. No tengo nada en contra de Andalucía. ¿Pero por qué cojones hablan tan mal? ¿Por el clima?, ¿Por las siestas infinitas?». En este comentario no solo ridiculiza la manera de hablar de los andaluces con su comentario «hablan tan mal», sino que también incluye el estereotipo de que los andaluces «siempre están durmiendo la siesta». Alguna de las respuestas que recibió este usuario fueron: "Ya estamos con lo de siempre», «a mí el laísmo me molesta mucho más que el andaluz» $\mathrm{O}$ «Por qué los madrileños creen que hablan bien? No tengo nada en contra de Madrid. ¿Pero por qué cojones creen que hablan bien? ¿Por el clima? ¿Por qué son simplemente subnormales?». Como podemos observar en las respuestas que Jomoru recibió, los ataques contra el andaluz no solo son injustos, sino que también suscitan enfrentamientos entre los andaluces y el resto de españoles (Jomoru, 2012).

\subsubsection{Televisión: series, programas y películas}

En segundo lugar, nos gustaría mostrar algunos ejemplos encontrados en la televisión. En la encuesta realizada para este artículo, el 66,2 \% de los participantes afirmó que recordaba alguna serie, película, canal o programa que utilizase personajes andaluces de manera humorística, como: Ocho apellidos vascos, Aquí no hay quien viva, Alli abajo, Aída, Médico de familia, La que se avecina, El club de la comedia, Toy Story, Mujeres al borde de un ataque de nervios, Vente a Alemania Pepe, El hormiguero, Hotel Transylvania, Farmacia de guardia, Ocho apellidos catalanes, Los Serrano, Torrente, Makinavaja, Polònia, Martes y Trece, Cuéntame cómo pasó, Bandolero, La resistencia, Fruitis, 
La vuelta al mundo de Willy Fog, El gato con botas, La niña repelente, Ana y los siete, Buscando el norte, Camera café, Tu cara me suena, Malviviendo, El chiringuito de Pepe y Shrek.

De las distintas series analizadas, destacamos la serie Juntas, pero no revueltas, El ministerio del tiempo y Fruitis. En Juntas, pero no revueltas, el personaje de Rosa representa a una camarera andaluza que tiene relaciones sexuales con todos los hombres que se cruzan por su camino. Rosa representa la parte humorística, inculta, torpe y cateta de la trama (Castro Gómez, 2016). Por ejemplo, en el episodio 24 de la serie, observamos cómo las risas aparecen cuando el personaje de Rosa se viste con un traje de flamenco y su hermana, también andaluza, se golpea con todo lo que se encuentra en la habitación. Es decir, en este capítulo observamos el estereotipo de que todos los andaluces bailan flamenco y se visten con trajes de lunares, así como el estereotipo de la gracia y la torpeza andaluzas (RTVE, 1006). En el capítulo 5 de la serie El ministerio del tiempo de RTVE, que trata sobre una sociedad secreta del gobierno, aparecen Picasso y Velázquez, ambos de origen andaluz: uno de Málaga y otro de Sevilla. Sin embargo, ninguno de los dos habla con acento andaluz en la serie, sino que ambos utilizan un dialecto castellano perfecto. Esto muestra la falta de voluntad que existe en la televisión española de mostrar la verdadera identidad de Andalucía, una tierra milenaria por la que han pasado grandes figuras de la historia cultural de España (Ramos López, 2017). Por último, destacamos la serie de Fruitis, una colectividad de frutas y verduras felices que viven cerca de un volcán. En esta serie, el personaje de Gazpacho representa el lado humorístico de la trama. Es el más «gracioso» de la serie: sabe bailar flamenco, es muy bromista y habla andaluz. Además, han utilizado como personaje a un gazpacho, un plato tradicional de Andalucía. Por ejemplo, en el episodio 2 (El enigma de los gigantes), todos los Fruitis salen del volcán en busca de un nuevo hogar y Gazpacho va haciendo palmas por el camino para animar al grupo. Sin embargo, Mochilo (el plátano), de vez en cuando, realiza algunos comentarios que fomentan los estereotipos contra el andaluz. Por ejemplo, en una ocasión, Mochilo le dice a Gazpacho: «Mucho cuento es lo que tú tienes, Gazpacho». En otra escena, Gazpacho se pierde y algunos Fruitis quieren ir a buscarle, pero Mochilo dice «no hace falta, estará durmiendo tranquilamente en la barcaza» (Ramos, 2017). Aquí observamos dos tópicos: el tópico de la «habladuría» de los andaluces y el mito de que los andaluces siempre están durmiendo la siesta. Esta serie es muy peligrosa para la dignidad del habla andaluza porque la ven los niños, que crecerán creyendo que los andaluces son como los muestras las series o películas que ven.

De los distintos programas analizados, destacamos El Hormiguero. En él, Pablo Motos ha despreciado el acento andaluz en varias ocasiones. En 
octubre de 2016, por ejemplo, Pablo Motos se burló del acento de Manolo Sarriá (humorista y actor malagueño) con el siguiente comentario: «Habla en perfecto castellano para que te entienda el concursante», «Me gustaría que hicieses las preguntas y ellos te contestasen, pero pronunciando todas las eses». Muchos andaluces se sintieron ofendidos y escribieron en las redes opiniones como «Pablo Motos riéndose del acento andaluz...qué gracioso, me parto», «Pablo Motos, yo hablo un perfecto andaluz», «Pablo Motos, eres un inculto» o «¿Qué pasa, que los andaluces no hablamos bien? Eres lamentable, Pablo Motos» (Ecoteuve, 2016).

De las películas analizadas, destacamos la película Ocho apellidos vascos, una comedia basada en los estereotipos, tanto vascos como andaluces. Su impacto humorístico se centra en el lenguaje que utilizan sus personajes. En esta historia, los estereotipos que observamos muestran a los andaluces como incultos, fiesteros, artistas, religiosos, extrovertidos, exagerados, graciosos, "parlanchines» y acogedores; mientras que a los vascos los presentan como fuertes, brutos, honrados, respetables, bebedores, serios, cerrados, tradicionales y separatistas (Belamendia Alegria, 2015). A modo de ejemplo, señalamos la primera escena de la película. Esta parte se desarrolla en un bar sevillano con bailarines y cantantes de flamenco, todos vestidos con trajes flamencos y bebiendo rebujito. Lo primero que hace Rafa al intervenir es contar un chiste sobre vascos, que más tarde es criticado por Amaia: «Estoh son dos vascoh que se encuentran y le dise el uno al otro "iOye Pachi!, ¡Que menterao que tu hija está en la cama con gonorrea!” y el otro dice “ $\mathrm{i} Y$ a mí que ostias, mientras que sea vasco!». Amaia lo critica y Rafa responde: «sin fartáh, ¿eh, muxaxa?, que porque tú seah de lah vajcongadah...», a lo que Amaia responde «iLa incultura de esta gente!», «iPanda de vagos!, solamente os levantáis de la siesta pa’ ir de juerga». Esta primera escena recoge muchos de los estereotipos que existen sobre los vascos y los andaluces. Muestran a los vascos como muy protectores y hablistas (solo permiten que sus hijos se relacionen con vascos) y a los andaluces como vagos, incultos y fiesteros (Martínez Lázaro, 2014).

\subsubsection{Radio}

$\mathrm{Al}$ analizar la radio, hemos observado que tanto en el manual de estilo de RTVA (Radio y Televisión de Andalucía), como en el de RTVE (Radio y Televisión Españolas) limitan el uso del dialecto andaluz. En ambos manuales, se equipara «lenguaje correcto» a «español estándar» y se defiende que el resto de dialectos y variedades no se pueden utilizar porque no se entienden en el resto de España (Ramos López, 2017). 


\subsubsection{Libros}

En relación a los libros analizados, destacamos la crítica que recibió $L a$ gramática sobre la lengua castellana de Antonio de Nebrija (1492), un sevillano del siglo XV-XVI, conocido por desarrollar la primera gramática castellana, así como otros diccionarios. Nebrija contribuyó al reconocimiento y prestigio de la lengua castellana, en su transición de lengua vulgar procedente del latín a lengua de cultura. Asimismo, participó en la consecución de una unidad nacional a través de una lengua común en todo el territorio reconquistado y en el posterior territorio conquistado (colonialismo español). Sin embargo, fue muy criticado en su época por el hecho de ser andaluz. Juan de Valdés, entre otros, criticó a Nebrija en varias ocasiones. Según Valdés, los andaluces no hablaban la misma lengua que se hablaba en la corte, sino una lengua inferior e incorrecta y, por tanto, no debería ser un andaluz el que escribiese la gramática castellana (Niederehe, 2004).

\subsubsection{Ambiente externo}

Por último, el ambiente externo, es decir, las personas que influyen en la visión que tenemos sobre la vida en nuestro día a día, nos impactan enormemente. El ejemplo que ponemos a continuación es un ejemplo político. La política ha supuesto un foco de críticas hacia el andaluz. Por ejemplo, en 2017, Enrique Sardá Valls, cónsul español de servicio en EE.UU., escribió en Facebook:

Hay q ver q. ozadia y mar gusto la de la susi. Mira q ponerse iguá q letirzia. $\mathrm{Cm}$ se ve $\mathrm{k}$ n.sabe na de protoculo ella tan der pueblo y de izquielda. nos ha esho quedar fatá a lo andaluse. dimicion ya (Santos, 2017).

En realidad, reprobaba que Susana Díaz hubiese llevado un traje parecido al de la reina Leticia en un evento malagueño e intentaba escribir con un acento supuestamente andaluz (Santos, 2017).

\subsection{ANÁLISIS DE MOTIVOS POR LOS QUE SE DESPRESTIGIA EL ANDALUZ}

Los casos mencionados solo son algunos de los muchos casos que hemos encontrado. Pero son suficientes para darnos cuenta de que los estereotipos andaluces siguen presentes en nuestros días y hacen mucho daño a la imagen de los andaluces y Andalucía. En la encuesta realizada para este artículo, hemos preguntado sobre los motivos por los que se desprestigiaba el andaluz. De las respuestas recibidas, hemos observado que no existen causas objetivas 
y reales por las que el andaluz deba considerarse como un dialecto inferior, sino que lo que existe es una falta de conocimiento sobre la historia lingüística de España y una falta de enseñanza del valor que tiene la diversidad lingüística de nuestro país (Castro Gómez, 2016).

\subsection{ANÁLISIS DE CONSECUENCIAS PARA LOS ANDALUCES}

Estos estereotipos y falsas creencias que se han difundido sobre los andaluces han perjudicado la imagen de Andalucía. Dado que muchos españoles no toman en serio a los andaluces, esto les perjudica gravemente en muchos aspectos de su vida, pero, sobre todo, a la hora de encontrar trabajo. Existen muchas limitaciones de trabajo para periodistas y presentadores de televisión andaluces. De hecho, para evitar un posible rechazo, muchos actores, locutores, periodistas y otros trabajadores se han visto obligados a esconder su acento para poder trabajar o acceder a un trabajo. Asimismo, muchos andaluces esconden su acento a la hora de hablar con otros hispanohablantes o a la hora de hablar en público porque creen que así les entenderán mejor o porque creen que es más correcto o formal. También, muchos andaluces se han visto obligados a utilizar un castellano (poco natural y forzado) para conseguir trabajo en otras comunidades autónomas (López González, 2018).

\subsection{ANÁLISIS DE MOTIVOS QUE REFUTAN LOS ESTEREOTIPOS}

Pero, hemos de decir que hemos encontrado una gran cantidad de motivos que nos enseñan que el andaluz es tan válido como cualquier otro dialecto y que refutan todos los estereotipos que hemos mencionado. Estos motivos los hemos dividido en: respuestas a los principales mitos, historia lingüística del andaluz, gramática andaluza, escritores y otros artistas andaluces importantes, riqueza léxica del andaluz y la Constitución española.

\subsubsection{Respuesta a los principales mitos}

Según las respuestas a los principales mitos, resulta incorrecto afirmar que el andaluz es ininteligible, vulgar o gracioso. El estereotipo de la ininteligibilidad es incorrecto porque el hecho de comprender o no a una persona, no resulta de su dialecto, sino de su persona y de su propia capacidad para hacerse comprender. Vamos a encontrar personas a las que no comprendamos en todos los dialectos; no solo en el andaluz. El mito de la vulgaridad 
tampoco es adecuado si se tiene en cuenta la historia, ya mencionada, de la lingüística española. El andaluz es una evolución del latín, al igual que el castellano, por lo tanto, es tan correcto como el castellano. Además, los vulgarismos los encontramos en hablantes de todas las comunidades autónomas de España, no solo en Andalucía. El mito de la gracia andaluza tampoco sería correcto porque la gracia depende de la personalidad de cada persona. Hay personas graciosas y personas sin ninguna gracia en todos los dialectos. Es cierto que muchos andaluces, como Chiquito de la Calzada o Dani Rovira han conseguido hacerse con su público, gracias al ingenio de sus chistes y monólogos. Pero, eso no quiere decir que el andaluz deba ser la base del humor (Castro Gómez, 2016).

\subsubsection{Historia lingüística del andaluz.}

Según la historia lingüística del andaluz, como ya hemos mencionado, el hecho de que el castellano se haya impuesto sobre el resto de dialectos no reside en causas relacionadas con la lengua, sino en causas extralingüísticas, por casualidades de la historia. Hemos observado que el andaluz ha evolucionado de una manera distinta al castellano y conserva muchas formas arcaicas cultas procedentes del latín. A modo de ejemplo, el diminutivo en andaluz se forma con los sufijos «-illo» e «-illa», que provienen de los artículos latinos ille e illa. Asimismo, el término andaluz «parí» (dar a luz), considerado como una palabra vulgar por el castellano, proviene del latín parere, y el término «preñá» (embarazada) procede del latín pregnare, mientras que el término «embarazar» procede del francés embarrasé, que quiere decir «avergonzado» (Heredia Jiménez, 2018, p. 43-94).

\subsubsection{Gramática en Andalucía}

Según la gramática utilizada en Andalucía, esta tierra no es una tierra de analfabetos. En la actualidad, los jóvenes andaluces reciben la misma educación que el resto de españoles. Además, en Andalucía no incurrimos en errores gramaticales del castellano como el leísmo, laísmo y loísmo, propios de la zona central de España. Asimismo, el andaluz no suprime, ni olvida nada, como suelen hacer las personas que tratan de imitar este acento, sino que sustituye; por ejemplo, no se omite la s final, sino que se aspira. Por último, los andaluces no hablan como escriben, sino que hablan en andaluz, pero escriben con un correcto castellano. Lo cierto es que la comunicación oral y escrita no tienen por qué ser exactas. Entre ellas existen grandes diferencias. 
Este fenómeno también ocurre con una gran cantidad de lenguas, como el francés, inglés o alemán (López González, 2018).

\subsubsection{Escritores y otros artistas andaluces importantes}

Andalucía no es una tierra de analfabetos, sino que ha sido la tierra de grandes figuras artísticas, poetas, escritores, pintores y músicos. De hecho, muchas figuras importantes de la literatura española han sido y son andaluzas (Heredia Jiménez, 2018, p. 125). Destacamos a Federico García Lorca, Antonio Machado, María Zambrano, Gustavo Adolfo Bécquer, Marco Anneo Lucano, Frasquita Larrea, Manuel Altolaguirre, Fray Bartolomé de las Casas, Cristobalina Fernández de Alarcón, María Rosa de Gálvez, Juan Ramón Jiménez, Elvira Lindo, Aurora Fuster Gallardo, Patrocinio de Biedma, Lorca, Alberti, Aleixandre, Cernuda, Emilio Prados, Rogelio Buendía, Rafael Zabaleta, Bartolomé Estaban Murillo, Diego Velázquez, Juan Valdés Leal, Julio Romero de Torres, Pablo Ruiz Picasso y Mateo Inurria (López González, 2018).

\subsubsection{Riqueza léxica del andaluz.}

Según el léxico del andaluz, el andaluz tiene una gran riqueza léxica, con palabras propias y términos arcaicos que ya no se utilizan en el resto de España. Es decir, el andaluz tiene palabras para significados que en el resto de dialectos del español no existen y los andaluces crean palabras nuevas para expresar aquello que quieren decir. En las encuestas realizadas para este trabajo, hemos recogido algunos ejemplos de andalucismos de diferentes regiones, así como sus posibles significados en castellano. Destacamos: cabetes (cordones de los zapatos), malafondinga (persona desagradable), trepar (tirar), pexá (mucho), sebaura (rozadura), sierso (sin gracia), bulla (prisa), encartar (venir bien), patochá (tontería), chominá (tontería), abarrotado (lleno), pillapelos (horquilla), revenío (alimento pasado), fullero (tramposo), sarcillo (pendiente), arresío (que tiene mucho frío), cochambroso (sucio), remear (imitar para burlarse), miaja (trozo de pan), acarajotao (empanao), jarmaso (porrazo), insorrible (tacaño), adrede (a cosa hecha), empercharse o emperchao (acoplarse a un grupo con el que no se tiene relación aparente), malaje (persona mala) y cancarrulla (dirigir mediante un espejo los rayos de sol hacia una persona o cosa). 


\subsubsection{Constitución española}

Por último, según la Constitución española, no deberíamos burlarlos de las variedades lingüísticas. Los casos en los que se discrimina el andaluz en Andalucía incumplen el Estatuto Andaluz de Autonomía en la promoción de los valores culturales de Andalucía y la protección de la lingüística andaluza; así como la Constitución española en cuanto al respeto de la pluralidad y diversidad lingüística y dialectal del país (Carrascosa Pulido, 2002).

\section{PROPUESTAS DE HABLA Y DEFENSA}

En cuanto a las sugerencias para la mejora de la dignidad del dialecto andaluz, una clave importante reside en el sistema educativo. La educación, tanto andaluza, como del conjunto español, debería explicar el origen, las características y la validez del andaluz en los colegios, así como dejar de corregir la manera de hablar de los alumnos andaluces. Los profesores andaluces, asimismo, deberían hablar con su propio acento y dejar de suavizarlo, cambiarlo o mezclarlo con el castellano. También se debería promover la creación de transcripciones fonéticas al andaluz en el ámbito educativo y fomentar la enseñanza de la fonética andaluza, que, desde luego, no es la misma que la castellana. Por otra parte, se debería defender y utilizar nuestro dialecto con orgullo, sin vergüenza, así como amar nuestra propia identidad para demostrar que no somos una tierra de incultos, sino que el andaluz culto es capaz de llegar a las tribunas públicas, tener un trabajo digno y ser respetado como cualquier otro español. Por último, la televisión y otros medios de comunicación deberían empezar a mostrar que el andaluz no solo representa al pobre y al inculto, sino también al rico, al inteligente, al elegante, al educado y al de buena posición (López González, 2018). Los medios de comunicación, al mismo tiempo que son la plataforma más peligrosa para el desprestigio del andaluz, también son (por su influencia y autoridad en la sociedad) la mejor vía para la proyección del prestigio andaluz. De esta forma, y solo de esta forma, acabaremos con la mentalidad estereotipada de la sociedad y conseguiremos que, en un futuro, este dialecto se reconozca como una variedad tan válida como las demás (Castro Gómez, 2016). 


\section{CONCLUSIONES}

En conclusión, los prejuicios lingüísticos no tienen un sustento real, sino que se producen por intereses políticos, económicos y casualidades de la historia. Algunos autores supremacistas, como Manuel Alvar y Gregorio Salvador, apoyan la idea de una lengua superior a otra. Sin embargo, estas ideas no valoran el hecho de que las lenguas (y con ello, nos referimos también a dialectos y hablas) están muy arraigadas a la cultura y, el hecho de permitir y fomentar la desaparición de una lengua por la supremacía de otra, está permitiendo la desaparición de una cultura y una visión del mundo. La implantación de un español estándar es una creación imaginaria, ya que no es más que la imposición de la variedad dialectal del castellano, que se considera como tal por razones extralingüísticas y nunca puramente lingüísticas. Las burlas, los prejuicios y el hecho de que se establezca un español común o estándar perjudica al resto de dialectos y hablas, que se desprestigian y consideran inferiores. España siempre ha sido una tierra de diversidad de lenguas, dialectos y hablas; por lo que, en lugar de la unidad del sistema lingüístico, se debería fomentar la continuidad de su tan característica diversidad (Muñoz Navarrete, 2009).

\section{REFERENCIAS}

Alvar, M. (2006). ¿Existe el dialecto andaluz? (Biblioteca Virtual) Miguel de Cervantes. Recuperado de: http://www.cervantesvirtual.com/obra-visor/existe-el-dialecto-andaluz-0/html/00e2f80e-82b2-11df-acc7-002185ce6064_6.html\#I_0_

Alvar, M. (2007). Hacia los conceptos de lengua, dialecto y hablas. (Biblioteca Virtual) Miguel de Cervantes. Recuperado de: http://www.cervantesvirtual.com/ obra-visor/hacia-los-conceptos-de-lengua-dialecto-y-hablas-0/html/00ec1fec82b2-11df-acc7-002185ce6064_3.html\#I_0

Belamendia Alegria, A. (2015). Ocho apellidos vascos. Un análisis de estereotipos vascos. Recuperado de la Universidad de Gotemburgo: https://gupea.ub.gu.se/bitstream/2077/46746/1/gupea_2077_46746_1.pdf

Cantó, P. (2018). ¿Por qué molesta que se hable con acento andaluz en "La Peste"? El Confidencial. Recuperado de: https://www.elconfidencial.com/cultura/2018-01-20/ la-peste-movistar-acento-andaluz-subtitulos_1507595/

Carrascosa Pulido, J. L. (2002). El habla en los informativos andaluces de radio y televisión y en el cine. Recuperado de https://docs.google.com/file/d/0B_Pa1oHa6OXsZElQbEdiX2F3RIU/edit?resourcekey=0-JL8jyLMbskesffjkfedoEg

Castro Gómez, M. L. (2016). La presencia del andaluz en los medios de comunicación. En R. Mancinas-Chávez. (Ed. 2016), Actas del I Congreso Internacional 
Comunicación y Pensamiento. Comunicracia y desarrollo social (pp. 1583-1600). Sevilla, España: Egregius.

Ecoteuve. (2016). Críticas a Pablo Motos por "menospreciar" el andaluz: "Habla en perfecto castellano para que te entienda". El Economista. Recuperado de: https:// ecoteuve.eleconomista.es/programas/noticias/7875167/10/16/Criticas-a-PabloMotos-por-reirse-del-acento-andaluz-de-Manolo-Sarria-Habla-en-perfecto-castellano-para-que-te-entienda.html

Heredia Jiménez, M. (2018). El idioma andaluz. ¿Es el andaluz un idioma? España: Editorial Almuzara.

Jomoru. (2012). ¿Por qué los andaluces hablan tan mal? Recuperado el 21 de marzo de 2020 de Foro Coches: https://www.forocoches.com/foro/showthread. php?t=2997576

Limón, R. (2017). El andaluz como arma para desprestigiar. El habla vuelve a ser un recurso de burla, pese a su gran valor. El País. Recuperado de: https://elpais.com/ cultura/2017/03/10/actualidad/1489167133_809200.html

López González, M. N. (2018). La dignidad del habla andaluza. Córdoba, España: Editorial Almuzara.

Manzano, A. (2017). Lengua andaluza: ¿Idioma, modalidad lingüística o dialecto? Revista de Pensamiento Andaluz. Recuperado de: http://pensamientoandaluz.org/ index.php/ali-manzano/145-lengua-andaluza-idioma-modalidad-linguistica-o-dialecto.html

Martínez Lázaro, E. (director) (2014). Ocho Apellidos Vascos. [Cinta cinematográfica]. Netflix.

Muñoz Navarrete, M. (2009). El supremacismo lingüístico. Recuperado de: http://hblog.nuevaradio.org/b2-img/navarrete_supremacismo.pdf

Niederehe, H. J. (2004). La Gramática de la lengua castellana (1492) de Antonio de Nebrija. En Sociedad Española de Historiografía Lingüística. (Ed. 2004). Boletín de la Sociedad Española de Historiografía Lingüística, 4 (pp. 41-52). España: SEHL.

Persànch, J. M. (2011). El andaluz: ¿Lengua criolla o dialecto castellano? Recuperado de Fundéu: https://www.fundeu.es/noticia/el-andaluz-lengua-criolla-o-dialecto-castellano-6603/

Ramos López, C. (2017). El desprestigio del andaluz y del canario en los medios de comunicación actuales. Recuperado de Repositorio Universitat Pompeu Fabra: https://repositori.upf.edu/bitstream/handle/10230/33978/Ramos_2017.pdf?sequence=1\&isAllowed=y Ramos, A. (2017). Por qué el personaje "gracioso" de los dibujos animados siempre tiene que tener acento andaluz. El Español. Recuperado de: https:/www.elespanol.com/social/20170127/189231410_0.html

RTVE. (1996). Juntas pero no revueltas - Rosa y Rosi. Capítulo 24 de la serie. Recuperado de: https://www.rtve.es/alacarta/videos/juntas-pero-no-revueltas/juntas-pero-no-revueltas-rosa-rosi/2825308/

Santos, P. (2017). Cesado el cónsul en EEUU por burlarse del acento de Susana Díaz. El Periódico. Recuperado de: https://www.elperiodico.com/es/politica/20170801/ consul-espana-eeuu-mofa-susana-diaz-andaluz-6202342 